\title{
Fuel Subsidies Versus Market Power: Is There a Countervailing Second-Best Optimum?
}

\author{
Morakinyo O. Adetutu ${ }^{1} \cdot$ Thomas G. Weyman-Jones $^{2}$
}

Accepted: 21 October 2019 / Published online: 5 November 2019

(c) The Author(s) 2019

\begin{abstract}
Fuel subsidies distort end-use prices below cost, resulting in overconsumption and huge environmental cost. On the other hand, the mark-up over cost due to the exercise of market power results in the social loss of consumer surplus. We open a new line of inquiry into the potential for a market-based solution from these two countervailing forces: can the two offsetting distortions conceivably achieve a second- best optimum? Relying on dynamic panel techniques and gasoline market data for 68 developing countries, we uncover an excessive second-best subsidy offset to market power mark-up on the order of 4.5. Our results indicate that the potential for policy failure strongly exceeds the potential for market failure in our model, and gasoline prices across our sample may not be aligned with vigorous anticlimate change policy.
\end{abstract}

Keywords Gasoline $\cdot$ Fuel subsidies $\cdot$ Market power $\cdot$ Pass-through $\cdot$ Second-best · Developing countries

JEL Classification C $3 \cdot \mathrm{L} 1 \cdot \mathrm{L} 2 \cdot \mathrm{Q} 4$

\section{Introduction}

Fuel subsidies are often employed by developing countries ${ }^{1}$ as instruments to alleviate poverty and promote social welfare. According to the IMF, global energy subsidies amounted to $\$ 5.3 \mathrm{tn}$ in 2015 , with developing countries sacrificing, on average, around $7 \%$ (versus $1.9 \%$ for OECD countries) of their GDP to provide these subsidies. The IMF computation of global fuel subsidies defines them as arising when consumer prices are below supply

\footnotetext{
1 This is particularly the case for net oil exporting or resource-rich countries where petroleum subsidies are often much larger. See IEA (2012) and Plante (2014).

Morakinyo O. Adetutu

morakinyo.adetutu@warwick.ac.uk

Thomas G. Weyman-Jones

t.g.weyman-jones@lboro.ac.uk

1 Global Sustainable Development, University of Warwick, Coventry CV4 7AL, UK

2 School of Business and Economics, Loughborough University, Loughborough LE11 3TU, UK
} 
costs plus environmental costs and general consumption taxes, rather than simply the difference between consumer prices and supply costs. Policies to use subsidisation of this nature may arise for a variety of socio-political reasons including help for low income households, and, as the IMF suggests, the degree of distortion from the equilibrium price may be considerable. We are careful in this paper not to use the term welfare optimum to identify the second-best outcome that arises from the countervailing forces of market power and subsidy because we have not explicitly included estimates of the social cost of carbon. $^{2}$ These would be needed if the aim was to pin down the welfare optimal outcome. For a sound and comprehensive treatment of that approach, see Parry et al. (2014). A major consensus in the fuel subsidy literature is that they distort prices and lead to socially inefficient levels of consumption (e.g. Davis 2014; Coady et al. 2017). First, they constitute a drain on government budgets, often resulting in scale imbalances. Second, they stimulate the overconsumption of oil resources, thereby limiting global efforts towards reducing greenhouse emissions. Third, the overconsumption arising from fuel subsidies indicate misallocation of scarce resources. ${ }^{3}$ Finally, fossil fuel subsidies encourage the "lock-in" for fossil-based technologies by limit the adoption of more efficient (low-carbon) technologies since they lower the opportunity cost of fossil fuels below consumers' willingness to pay. ${ }^{4}$

On the other hand, a large body of evidence in the industrial organization literature indicates that the excessive mark-up arising from the exercise of market power results in producer cost inefficiency and the loss of consumer surplus (e.g. Martin 1988; Delis and Tsionas 2009). However, conservationists prefer the excessive mark-up over cost as a necessary condition for capturing the external cost of environmental damage from fossil fuel consumption (see Medlock 2011). Although higher prices might eliminate overconsumption and internalise the negative externality arising from pollution, deadweight losses can also arise from excessive mark-ups (Newbery 1995). The price distortion due to market power in fuel supply is only aligned with the environmental cost signal if it exceeds any market power distortion that applies to prices in general. While we do not have specific evidence on this, retail petroleum supply is widely recognised to be dominated by large scale private and state-owned companies. It is also the case in many developing countries that retail petroleum prices are administered through state owned suppliers which may pursue both revenue-raising and socio-political goals. This factor could offset the market power impact and, if so, would contribute towards any finding that the subsidy effect dominated the market power effect in the determination of the price signals. ${ }^{5}$

Given the presence of these two market distortions (subsidies and market power); the problem facing the social planner ${ }^{6}$ is well encapsulated in some salient questions: is there a countervailing offset from these two opposing forces? Can these two offsetting distortions conceivably achieve a second-best optimum? What is the net impact of these two

\footnotetext{
2 We are indebted to a reviewer for emphasising this point.

3 It is almost always the case that high-subsidising countries are better off directing their resources towards high-priority areas in education, health, and infrastructure, which are likely to benefit low and middleincome households (Coady et al. 2010).

4 These arguments underscore the growing consensus in current research and global policy discussions on the need to urgently reform fossil fuel subsidy is understandable. For instance, several notable international bodies such as the IMF, IEA, UN and IPCC all highlight the need to urgently reform fossil fuel subsidies, often citing the many adverse consequences of the wedges between costs and end-use energy prices.

5 These points are due to a reviewer.

6 This could be the government, an energy regulator or an international environmental agency. See Newbery (1995) for discussions on the regulator's dilemma in this trade-off.
} 
distortions? The intention in the paper is to investigate this trade-off between the upward pressure on fuel prices from exercise of market power and the downward pressure from fuel subsidies, recognising that both effects have an impact on the demand for emissioncreating fuel. Thus, the emissions impact is left implicit rather than being treated as an explicit emissions-directed policy. ${ }^{7}$ Since we have not attempted to take marginal external costs in the form of the social cost of carbon into account as well as the subsidy and market power aspects, we must be clear that the analysis in this paper is about the trade-off between fuel price subsidy and market power alone. Therefore, the aim of the paper is to investigate the extent to which a subsidy to reduce the fuel price moves the economy away from the first best equilibrium that would prevail in the absence of market power. If market power is present as well then this may reduce the divergence from the optimum arising from a subsidy, if the market power effect stands in for what would be the impact of tax to reflect marginal external cost.

This potential trade-off is essentially reflected by the plots in Fig. 1, which illustrates the relationship between petroleum subsidy share of GDP and petroleum-related carbon emissions in 2013. As seen in Fig. 1, there is a positive correlation between emissions from petroleum use and fuel subsidies, demonstrating that high welfare-based petroleum subsidies are not compatible with fossil-related emissions reduction.

A necessary condition for the design of policy instruments and interventions in energy markets is a clear understanding of the interaction between jointly reinforcing market failures. Second, understanding the trade-off between these market distortions provides valuable insight on the potential net effect of policy interventions. This is because policies targeted at one market failure may affect the outcome of policies required to address the other. To answer the interrelated questions above, we derive a price setting model for gasoline across developing countries which embodies fuel consumption subsidies and market concentration. Our aim is to provide a joint estimation of these market distortions and the implicit trade-off between both forces. As far as is known, this study is the first to assess the trade-off in gasoline markets in this way, and it is a timely contribution to the ongoing discussion on the low-carbon development of emerging economies. For instance, the Intergovernmental Panel on Climate Change (IPCC) projects a 50\% rise in transport sector emissions by 2030, relative to 2015 levels; driven mainly by regional shifts in transport energy use. ${ }^{8}$ This study therefore assesses two of the critical determinants of these regional shifts.

To give a flavour of our approach, petroleum subsidies will be measured as the difference between domestic retail fuel prices and international spot prices, adjusted for transport, distribution and retail costs, while marginal supply cost is the ex-refinery price similarly adjusted; both variables are sourced from the IMF. Our empirical strategy embodies an instrumental variable (IV) system of equations where we combine a demand model with a model of supply aspects of the market. We are able to identify three important parameters: (i) a parameter representing the impact of gasoline subsidies (ii) a market conduct parameter to capture the role of market concentration, and (iii) the semi-elasticity of

\footnotetext{
7 We owe this clarification to a reviewer.

8 The IPCC projects the share of non-OECD countries in transport sector energy use to reach $46 \%$ by 2030 , up from $36 \%$ in 2014.
} 
demand, to account for consumer behaviour. Our empirical tests are based on a comprehensive data set for 68 developing countries, covering the period 2000-2013. ${ }^{9}$

We provide econometric evidence that the distortions arising from petroleum subsidies far exceed the inefficiency resulting from market concentration. Specifically, the subsidy effect is more than four times the market power mark-up. These fuel subsidy distortions are consistent with our finding of some incomplete cost pass-through into retail gasoline prices, which we estimate at 0.67 in the short run and 0.84 in the long run, i.e. after the elapse of 5 years. The short-run estimate is significantly different from one at the one percent significance level, but the long-run estimate is not. Underlying our findings is the instrumentation for gasoline subsidies, which reveals the overbearing influence of the equity objectives of oil-producing countries, which are fulfilled by endowment distribution through end-use petroleum subsidies. Our results therefore indicate that the deadweight loss from policy failure far exceeds the inefficiency losses arising from market failure/mispricing.

The remainder of the paper is organised as follows. Section 2 provides a review of related literature on pass-through and market power. Sections 3, 4 and 5 describe the theoretical model, the estimation strategy and estimation issues. Section 6 describes our data set, while Sect. 7 contains the econometric results and study findings. Section 8 concludes.

\section{Related Literature}

Two literature resources can be drawn upon in this paper: (i) the evidence on limited cost pass-through/impact of subsidies on end-use fuel prices and (ii) the evidence on the impact of market power in domestic fuel markets, since market power provides a countervailing second-best influence on domestic prices that may offset the impact of national fuel pricing policies. We reflect on each literature in turn.

Although the issue of petroleum subsidies has received considerable attention in the literature ${ }^{10}$ there is hardly any cross-country evidence ${ }^{11}$ regarding the extent to which marginal cost is transmitted into retail petroleum prices. The IMF (2015) subsidy definition gives some indication that fuel price subsidies fail to cover externality costs and therefore implies that market power or administered pricing fails to internalize the externalities. Taking the IMF's (2015) suggestion as a starting point therefore, the purpose of the paper is to explore this possibility further in a systematic panel data econometric approach.

Accounting for marginal cost pass-through is a crucial starting point for the analysis of the net effects of distortions above/below cost arising from market power and subsidies. In short, marginal cost represents the theoretical reference point against which both distortions are evaluated, since the distortions embody wedges between prices and costs (see Newberry 1995; Hall 1988 for a discussion on the intuitive importance of the price-cost relationship).

A few IMF and World Bank working papers, such as Baig et al. (2007), Coady et al. (2010) and Kojima (2012) have considered crude oil price pass-through in fuel markets across several countries. Other studies include Beers and Strand (2013) who estimated the

\footnotetext{
${ }^{9}$ Our sample size is strictly determined by availability of reliable and consistent data on supply costs and retail prices of gasoline.

10 For instance, Plante (2014), Davis (2014), Larsen and Shah (1992).

11 The closest relatives are mostly country-specific (especially US) crude oil pass-through studies such as Borenstein and Shepard (2002), Bachmeier and Griffin (2003) and Atil et al. (2014).
} 


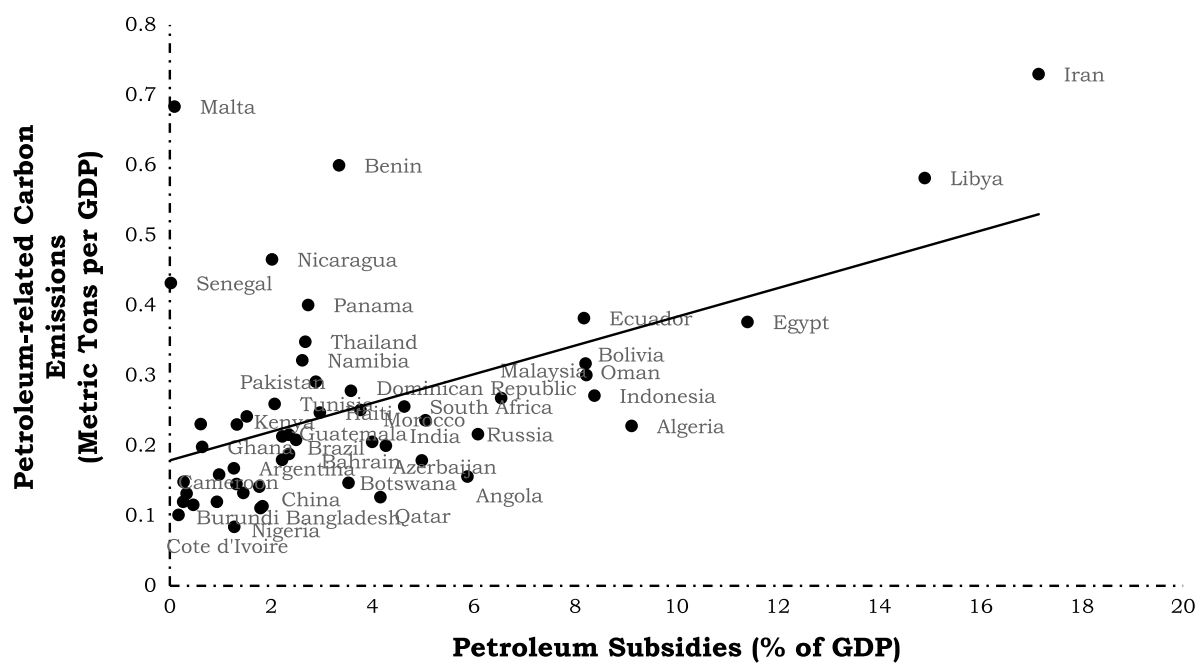

Fig. 1 Petroleum Subsidy \% of GDP versus Carbon Emissions in 2013

impact of a range of social and political variables on end retail petroleum prices. A key challenge with the studies above is that pass-through is simply derived as the ratio of absolute change in domestic retail prices to the absolute change in international crude prices. Implicit to this pass-through approach is the assumption of homogenous market conditions, since the studies ignored cross-country heterogeneity in their analysis.

More recently, Beers and Strand (2013) addressed the issue of heterogeneity in their pass-through analysis by controlling for a range of social and political variables. However, as in the previous studies, they also employed international crude oil price as a measure of world fuel price. Further, their model also ignored market aspects relating to market concentration and national fuel price policy.

This paper makes several contributions to the empirical literature. First, none of the previous studies evaluated "complete" cost pass-through to retail petroleum products, considering their use of crude oil price as a single representation of marginal cost. ${ }^{12}$ Based on this approach, the studies above implicitly assume that crude oil prices can fully reflect or approximate the marginal cost of refined petroleum products. ${ }^{13}$ Asplund et al. (2000) and Meyler (2009) show the two crucial stages between crude oil prices and retail prices: (i) refining and (ii) distribution activities. Hence, to the extent that these downstream costs contribute to supply costs, the widely adopted crude price approach ignores significant variations in other cost drivers.

In contrast to all the previous cross-country studies, we directly investigate marginal cost pass-through for gasoline. Ideally, we would like to have analysed a wider range of fuel commodities the focus on gasoline at least allows us to develop a feasible modelling

\footnotetext{
12 Crude prices represent less than $60 \%$ of the marginal cost of supplying a litre of gasoline, with significant cost elements arising from downstream segments of the production chain relating to refining, distribution, marketing and taxes. See for example https://www.eia.gov/petroleum/gasdiesel/ or https://www.giz.de/ expertise/downloads/giz-2015-en-ifp2014.pdf.

13 In part, the dearth of evidence on marginal cost pass-through reflects the difficulty in obtaining observable data on marginal supply costs for refined petroleum.
} 
approach given the limited availability of data for a wider range of products. This approach is arguably important for a number of reasons. First, the underlying economic theory indicates that firms' supply (pricing) decisions are based on changes in (slope of the) marginal cost. The price-marginal cost relationship also provides useful insight on the existing market structure via information on seller mark-up.

Second, our marginal cost approach allows us to capture the downstream segment of the gasoline supply chain. Borenstein et al. (1997) showed that pass-through in gasoline markets reflect downstream factors such as inventory adjustment, market power of sellers etc., which are impossible to observe using crude price data. Moreover, inferences about wedges between costs and retail prices are likely to be more reliable for a marginal cost analysis, given that market interventions employed by governments usually occur in the downstream part of the petroleum supply chain. ${ }^{14}$ Hence, unless a marginal cost approach is adopted, it is impossible to fully assess the wedge between supply cost and retail prices. This makes it practically impossible to estimate distortions above/below costs. In reality, both distortions are intimately related to cost pass-through in petroleum markets, and understanding their role can form a basis for better-designed reforms.

Turning now to the market conduct and market power literature, we use this to take the first steps in setting up the econometric model. To derive a price equation for our passthrough analysis, it is necessary to model the industry behaviour into which the national policy is embedded. In this case we draw on the industrial organization literature that stems from the work of Appelbaum (1982), Bresnahan (1982), Lau (1982) and Weyl and Fabinger (2013) to identify market conduct; and which proceeds through many applications to different industries such as Lopez et al. (2002) on the food processing industries, Shaffer (1993) and Angelini and Cetorelli (2003) on banking systems, and Kutlu and Sickles (2012) on airlines.

The early work in this field established the necessary and sufficient conditions for identification of market conduct parameters from aggregated industry wide data. Subsequent applications estimated the model to establish regulatory and efficiency implications in particular industries. Corts (1999) showed that the equilibrium concepts in the analysis required careful specification of the dynamic oligopoly game assumptions involved, and Kutlu and Sickles (2012) derived a particular random coefficients approach for the estimation of market conduct parameters in dynamic games.

In this paper, we outline the market conduct parameter analysis and then show that the identification issue is resolved using a theorem of Lau (1982) that exploits the availability of prior information on industry marginal cost. We address the issue of dynamics by using the insights of Borenstein and Shepard (2002) and Kutlu and Sickles (2012) on lagged responses by market agents, given that our panel data sample allows us to exploit the GMM estimation procedures within a dynamic panel data analysis (Arellano and Bond 1991). ${ }^{15}$

\footnotetext{
14 These extensive interventions include pump price regulation, lower fuel taxes, reduction in state-owned refinery margins, direct post-tax subsidies etc., which occur ex-crude oil prices.

15 See Bond (2002) for a useful survey.
} 


\section{Modelling Fuel Markets}

We proceed by assuming a domestic industry producing a homogeneous output $Y$ in each of $I$ firms: $y_{\mathrm{i}}$ so that $Y=\sum_{i} y_{i}$. The market price of the homogeneous output is $P$ and the market demand depends on this price and a vector of demand-shifting variables $\mathbf{z}$ :

$$
Y=F\left(P, \mathbf{z}^{\prime}\right)
$$

The market demand curve is assumed to be invertible: $P(Y)=F^{-1}\left(Y ; \mathbf{z}^{\prime}\right)$. This market structure is sufficiently general to accommodate the special case where a state-owned company sets administered prices that incorporate a subsidy element as we show below. To develop an industry wide pricing model, we follow a widely used approach, e.g. Appelbaum (1982), Bresnahan (1982) and Weyl and Fabinger (2013). In Weyl and Fabinger (2013), the authors treat pass-through of a specific tax as a motivating force for a wide range of comparative static effects across the field of applied economics. Our model represents a simplified version of their extremely rich general asymmetric imperfect competition model but one that is tailored to the limited availability of data. The key constraint is that their generalised market conduct variable requires interactions which in practice with limited data can only be handled by using relative market shares. For this reason, we have adopted the approach which includes the HHI market concentration index in the specification. The typical firm's output decision in the absence of administered prices is

$$
P\left(1-\left(s_{j} \theta_{j} / \varepsilon\right)\right)=M C_{j}
$$

In (2), $M C_{j}$ is the firm's marginal cost, $\varepsilon \equiv-(d Y / d P)(P / Y)$ is the market price elasticity of demand written as a positive value, $s_{j}$. is the market output share of the firm indexed $j$, and finally the term $\theta_{j}=1+d \sum_{i \neq j} y_{i} / d y_{j}$ is referred to as the conjectural variation used by firm $j$ in calculating the effect of its output change on the behaviour of the other firms; sometimes it is simply called the firm's 'conduct parameter'. The firm knows that a oneunit increase in its own output increases total industry supply by one unit plus the perceived impact of the firm's one-unit output increase on the output behaviour of all the other firms.

We are analysing industry-wide data; therefore, we aggregate from the individual firm's equilibrium condition in (2). The weighted average Lerner Index for the industry is

$$
L I=\left(P-\sum_{i} s_{j} M C_{j}\right) / P=(P-M C / P)=\sum_{j}\left(s_{j}^{2} \theta_{j} / \varepsilon\right)=(\Theta / \varepsilon) H
$$

Here, three transformations have been made. The share-weighted marginal costs are written as the aggregated industry marginal cost, $M C$. Then the individual firm market conduct parameters are assumed to be constant across all firms in the industry so that $\Theta$ represents the industry market conduct parameter. Finally, $H \equiv \sum_{i} s_{i}^{2}$ is defined as the Herfindahl-Hirschman index of market concentration. ${ }^{16}$ In the Weyl and Fabinger (2013) version of (3) the concentration index is subsumed into the general conduct parameter in cases where each firm's market share is identical. We can estimate the additive price equation to represent the supply side of the market by writing from (3)

\footnotetext{
${ }^{16}$ Expressing market shares as decimals means that $H$ lies between zero (highly competitive) and one (highly concentrated).
} 


$$
P=M C+[(\Theta / \varepsilon) H] P=M C+[(\Theta / \eta) H]
$$

In the final term on the right-hand side of Eq. (4), we have used the parameterization of $\eta \equiv \varepsilon / P \equiv-(1 / Y)(d Y / d P)=-d \ln Y / d P$. This term is the semi-elasticity of demand. The market conduct parameter is interpreted as:

$$
\begin{gathered}
\Theta=0 \rightarrow \text { zero market power or competition } \\
0<\Theta \leq 1 \rightarrow \text { positive market power }
\end{gathered}
$$

when there is positive market power, the proportional price marup over marginal cost is $H / \varepsilon$. with the limit of $1 / \varepsilon$ in the case of monopoly.

Many countries ensure that retail gasoline prices are administered for social and political purposes and we model this by superimposing on the equilibrium pricing rule a national energy pricing policy in each country which is represented here by an additional variable $S \geq 0$ representing the subsidy designed to ameliorate the income distribution effects of global energy price changes or to fulfil other environmental objectives.

There is an issue about the form of regulated market mechanism that is used in countries applying the type of fuel subsidies that we are discussing. ${ }^{17} \mathrm{~A}$ simple subsidy in an otherwise unregulated market does fit exactly into our framework in Eqs. (2) and (3). In countries where the consumer protection takes the form of administratively capped retail prices, pass through does not necessarily reflect the same comparative static effects that would operate in an unregulated market, therefore our derivations can in that case only be regarded as a first-order approximation and the coefficients on input prices and concentration will only approximately reflect pass-through and market power aspects. Nevertheless, a market equilibrium will still emerge. The administrative price cap changes the shape of the market demand curve (it has both horizontal and downward sloping segments) but production is still located at the intersection with the industry marginal cost curve. In this event, a price-capped profit maximising monopolist recovers its profitability by eliminating any X-inefficiency that would be tolerated in an unregulated monopoly, as suggested by Leibenstein (1966). In this way, the decomposition in Eq. (4) can still be applied as a modelling framework.

After adding exogenous supply side variables, $\mathbf{x}$, we obtain, where $\alpha<0$ in the subsidy case, $(\alpha>0$ in the case of an excise tax).

$$
P=M C+\alpha S+(\Theta / \eta) H+\mathbf{x}^{\prime} \boldsymbol{\beta}
$$

This expression of the industry equilibrium gives rise to a second-best analysis, since totally differentiating (5) produces

$$
d H /\left.d S\right|_{P=\bar{P}}=-\alpha \eta / \Theta
$$

This informs us that the equilibrium price will be unchanged at $P=\bar{P}$ if the increased exercise of market power $\Delta H>0$ is exactly offset by the effect of an energy price subsidy $\Delta S>0$ in the trade-off ratio: $-\alpha \eta / \Theta$. In short, the role of market power (captured through the critical parameters $\Theta$ and $\eta$ ) is a countervailing force that may increase pass-through and offset government fuel subsidy policy or the general use of administered prices for policy reasons. Consequently, the concentration effect, $d H$ and the subsidy effect $d S$ allow for an evaluation of the net impact of country wise variation in the fuel price policies on

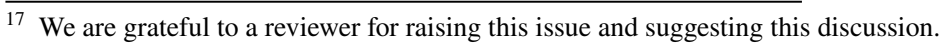


end-use prices. Our model therefore allows for an analysis of the countervailing equity or environmental price distortion through administered prices available to offset the inefficiency arising from the impact of market power, and vice versa. The two distortions working to offset each other could conceivably achieve a second-best optimum.

Taking Eq. (5) allied with Eq. (1) for the market demand; we obtain a simultaneous equation system for the market. This has the effect of making the equation system given by (1) and (5) recursive: the price variable in the demand function in (1) can be replaced by the equilibrium price from Eq. (5) without adding endogenous variables. Then if the semielasticity of demand parameter, $\eta$, can be consistently estimated and identified from (1) it can be used to identify the market conduct parameter $\Theta$.

An issue that is critical to the estimation of the model is the identification of the parameters of interest. Three parameters are critical in particular: the impact of the subsidy policy, $\alpha$, the impact of the market conduct parameter, $\Theta$, the semi-elasticity of demand, $\eta$. However, these enter non-linearly, and there is the further complication of the role of marginal cost, $M C$. The analysis in Lau (1982) is helpful here because if there is prior information about the level of marginal cost, then the market conduct parameter cannot be identified in only a very limited case.

A second issue that may be critical arises from Corts' (1999) observation that dynamic considerations can be important. Kutlu and Sickles (2012) also consider the issue of dynamics. These authors directly model the explicit dynamic games under different assumptions. On the other hand, Borenstein and Shephard (Borenstein and Shepard 2002) show that costly adjustment of production and inventories mean that fuel prices will respond to crude oil shocks with a lag, and that the adjustment of prices depends on market power. Hence, we exploit the role of partial adjustment within dynamic panel data modelling to address the issue of dynamics.

\section{Estimation Strategy}

To estimate our specified models, we assume the existence of a panel data sample for $n=1 \ldots N$ countries and $t=1 \ldots T$ time periods. We expect $N$ to be considerably larger than $T$. Equation (6) below is the estimating equation analogous to the long-run relationship between retail fuel prices, marginal cost and other exogenous factors. However, given the dynamic considerations above, it is very likely that retail fuel price adjustments to changing costs would be greater in the long run. This is consistent with the widely held notion in the literature, which tends to distinguish between short-run (SR) and long run (LR) elasticities. Additionally, in practice, the implementation of changes in fuel price policies (relating to taxes and subsidies) typically occur with considerable lags (see Alm et al. 2009). Borenstein and Shepard (2002)demonstrate the same impact from market power. Hence, we introduce the slow adjustment of retail fuel prices using a partial adjustment mechanism,

$$
P_{n t}=\gamma P_{n t-1}+\alpha_{1} M C_{n t}+\alpha_{2} S_{n t}+\alpha_{3} H_{n t}+\mathbf{x}_{n t}^{\prime} \boldsymbol{\beta}+\theta_{n}+\lambda_{t}+\varepsilon_{n t}
$$

where $P_{n t}$ is the domestic end-use price in country $n$ in period $t . H_{n t}$ captures the role of market concentration in domestic fuel markets. $S_{n t}$ represents the subsidy or administered fuel pricing policy, $\mathbf{x}_{n t}^{\prime}$ is a vector of supply-side characteristics that determine prices; $\theta_{n}$ and $\lambda_{t}$ are unobserved country and year effects respectively; $\varepsilon_{n t}$ represents random 
disturbance terms. $\alpha_{1}=\partial P_{n t} / \partial M C_{n t}$ is the degree of cost pass-through and $\gamma$ is the adjustment speed of retail prices, so that SR and LR pass-through ${ }^{18}$ can be written as:

$$
\zeta_{S R}=\alpha_{1} ; \quad \zeta_{L R}=\alpha_{1} / 1-\gamma
$$

If $\alpha_{1}=1$, we can conclude that there is full pass-through in the short run, and $\zeta_{L R}=1$ implies full pass through in the long run, while $\alpha_{1}<1$ and $\zeta_{L R}<1$ indicate incomplete pass-through of international prices: a wedge exists between the international fuel and domestic prices. On the other hand, $\alpha_{2} / \alpha_{3}$ indicates the second-best trade-off between market power and fuel subsidy. The model system is completed by the demand function based on (1) and specified in (8):

$$
\ln Y_{n t}=\varphi \ln Y_{n t-1}+\delta P_{n t}+\mathbf{z}_{n t}^{\prime} \boldsymbol{\mu}+\omega_{n}+\rho_{t}+\epsilon_{n t}
$$

where, as in the price equation in (6), $P_{n t}$ is retail fuel price. $\mathbf{z}_{n t}^{\prime}$ is a vector of logged demand-side characteristics that determine prices; $\omega_{n}$ and $\rho_{t}$ are unobserved country and year effects respectively; $\epsilon_{n t}$ are random disturbance terms. We have given the demand function in (8) the same adjustment and error structure in principle as the price Eq. (6), since lagged responses in demand to changes in fuel prices and income are to be expected, given that consumers require significant time to turn over their energy-using capital stock (mostly motor vehicles in the case of gasoline). Note also that the coefficient on the domestic price variable in (8) is the semi-elasticity: $\delta=-\eta=-\varepsilon / P$. The term $-\alpha_{1} \eta=-\alpha_{1} \delta$ measures the market conduct parameter. Our objective is to estimate the equation system given by (6) and (8).

\section{Estimation Issues}

There are practical econometric problems with identifying the key parameters in this study via the estimation of the equation set (6) and (8) above. First, they are dynamic econometric models that can be complicated by the endogeneity of the lagged price and demand variables. Second, this problem may be compounded by the endogeneity of the subsidy variable, $S_{n t}$ : there are at least three sources of endogeneity pertaining to the fuel subsidy variable in Eq. (6). First, $\theta_{n}$ captures fixed unobserved country heterogeneity, which might include persistent factors (e.g. policy preferences, socio-political and climatic conditions) that are approximately fixed over the time frame of our data sample. Because the subsidy variable $S_{n t}$ is likely to be influenced by these time-invariant factors, $\theta_{n}$ is potentially correlated with $S_{n t}$.

Secondly, there is great potential for reverse-causality, such that $P_{n t}$ could influence $S_{n t}$. For instance, as shown by the properties of our data set, the fuel subsidisers are largely resource endowed countries who attempt to shield end-use consumers from rising fuel prices by intervening (with large subsidies) to limit the degree of cost pass-through to domestic fuel prices. Hence, petroleum subsidies are often higher during periods of higher petroleum prices (see Coady et al. 2010). Furthermore, since governments in some of these countries are known to set end-user prices within certain thresholds, the size of the fuel

18 The long-run estimates of the subsidy and market power effects are derived in similar fashion. 
subsidy is a function of the target price. In effect, the target retail fuel price influences the size and persistence of the subsidy offset.

Thirdly, $\varepsilon_{n t}$ includes other random shocks which may explain the variations in $S_{n t}$. For instance, international oil price shocks or geo-political developments can affect sampled countries in different ways, e.g. oil rich subsidisers are likely to experience shocks to revenues or incomes during periods of negative oil price shocks which may limit their budgetary scope for petroleum subsidies. This problem could further complicate the endogeneity problem, since $S_{n t}$ would be correlated with $\varepsilon_{n t}$. This will bias the estimated coefficient on $S_{n t}$ downwards towards zero. ${ }^{19}$

Given the endogeneity issues discussed above, estimating (6) or (8) under the assumption of orthogonality of the regressors is not likely to produce consistent estimates. Hence, estimating the model parameters by ordinary least squares (OLS) will produce biased estimates. Dynamic panel data techniques offer solutions to the problems of endogeneity and heterogeneity identified above. First, we can control for the selection problem based on time-invariant country-specific effects $\theta_{n}$ by applying first differences to $(6)^{20}$ :

$$
\Delta P_{n t}=\gamma \Delta P_{n t-1}+\alpha_{1} \Delta M C_{n t}+\alpha_{2} \Delta S_{n t}+\alpha_{3} \Delta H_{n t}+\Delta \mathbf{x}_{n t}^{\prime} \boldsymbol{\beta}+\Delta \lambda_{t}+\Delta \varepsilon_{n t}
$$

This removes the country-specific effects, but the transformed error term is now correlated with the right hand side variables: $\Delta \varepsilon_{n t}=\left(\varepsilon_{n t}-\varepsilon_{n t-1}\right)$ is correlated with $\Delta P_{n t-1}=\left(P_{n t-1}-P_{n t-2}\right)$ since $\operatorname{corr}\left(P_{n t-1}, \varepsilon_{n t-1}\right) \neq 0$. This still means that OLS is inconsistent and hence, panel data (FE) estimators do not provide consistent estimates. However, we can search for instrumental variables correlated with $\Delta P_{n t-1}=\left(P_{n t}-P_{n t-1}\right)$ but orthogonal to $\Delta \varepsilon_{n t}=\left(\varepsilon_{n t}-\varepsilon_{n t-1}\right)$, with many possible instrumental variables arising from the moment conditions on the error terms. In this case, the Generalised Method of Moments (GMM) estimator is appealing. Ignoring the other exogenous variables for the moment, the instrument matrix for each cross section is the following array ${ }^{21}$ :

$$
\mathbf{Z}_{n}=\left[\begin{array}{ccccccc}
P_{n 1} & 0 & 0 & \ldots & \ldots & 0 & 0 \\
\vdots & \vdots & \vdots & \vdots & \vdots & \vdots & \vdots \\
0 & \ldots & \ldots & 0 & P_{n 1} & \ldots & P_{n T-2}
\end{array}\right]
$$

The moment equations are:

$$
E\left(\mathbf{Z}_{n} \Delta \boldsymbol{\varepsilon}_{n}\right)=0 ; n=1 \ldots N
$$

where $\Delta \varepsilon_{n}=\left(\Delta \varepsilon_{n 3} \ldots \Delta \varepsilon_{n T}\right)^{\prime}$. Applying a quadratic loss criterion with weighting matrix inversely proportional to the variances of the moments leads to the Arellano-Bond (AB) two-step difference GMM estimator (Arellano and Bond 1991) where the $\Delta \hat{\varepsilon}_{n}$ are consistent estimates of the first difference residuals from a preliminary consistent estimator. A one-step estimator is available with a simpler weighting matrix which does not depend on any estimated parameters. The two-step estimator offers a small gain in efficiency over the one-step but suffers from downward bias in its standard errors. However, Windmeijer (2005) provides the finite sample correction to the standard errors of the two-step estimator.

\footnotetext{
19 Similar arguments are applicable to the endogeneity of retail prices within the demand model in (14). See for instance Nakamura and Zerom (2010) for some arguments on price endogeneity within demand functions.

20 Similar arguments apply to Eq. (11).

21 This instrument matrix can be expanded by adding the exogenous variables.
} 
The difference GMM estimator uses lagged levels of the dependent variable as instruments for the first difference equation, but these may be weak instruments. Arellano and Bover (1995) and Blundell and Bond (2000) also introduced the system GMM estimator which uses lagged differences as instruments in the levels equation. One relevant attribute of the GMM estimator is that, apart from using 'internal instruments' (i.e. lagged values of the instrumented variables), it permits the inclusion of 'external instruments', which allows us to exploit all the information available in our data sample. ${ }^{22}$

Fitting Eqs. (6) and (8) in the first-difference, estimating form is the starting point of the analysis. To compare parameter values of interest, i.e. $\delta, \varepsilon, \eta, \Theta, \alpha_{1} \alpha_{2}, \alpha_{3}$, it is necessary to have a consistent set of transformations for these equations, which we set out as follows:

$\hat{\delta}=\hat{\eta}$ and therefore $\hat{\varepsilon}=\hat{\eta} \bar{P}_{n t} \quad$ semi-elasticity, i.e. percentage change in demand from a 1-unit price change in currency units (US\$PPP) identified using (8) and transformation to elasticity at sample mean

$\hat{\alpha}_{1}=\partial P_{n t} / \partial M C_{n t} \Rightarrow \hat{\alpha}_{1}\left[\overline{M C}_{n t} / \bar{P}_{n t}\right]$ elasticity of domestic price with respect to marginal cost (pass through) from (9)

$\hat{\alpha}_{2}=\Delta P_{n t} / \Delta S_{n t} \quad$ response of domestic price with respect to fuel subsidies from (9).

$\hat{\alpha}_{3}=-\hat{\Theta} / \hat{\eta} \Rightarrow \hat{\Theta}=-\hat{\alpha}_{3} \hat{\eta}=-\hat{\alpha}_{3} \hat{\delta} \quad$ market conduct parameter identified using (6) and (8).

The price equation in this set-up is linear with variable elasticities while the demand equation can be generally log-linear but with price entering as the level of the variable so that the semi-elasticity is identified and estimated, allowing for the estimation and identification of the market conduct term.

\section{Data}

Our data sample spans the period 2000-2013 for 68 developing countries across a broad geographical coverage which is a good representative sample of developing countries, (see "Appendix" for a list of sampled countries). We define petroleum subsidies following the widely used "price-gap",23 approach (e.g. Larsen and Shah 1992; IMF 2013), measured as the difference between domestic retail fuel prices and international reference prices, adjusted for transport, distribution and retail costs.

While the reference prices reflect the price of petroleum on a competitive (undistorted) international market, the domestic prices reflect the end-user prices. The reference prices are adjusted for each country using downstream cost data (see IEA 1999). For instance, the reference price for a petroleum exporter is the export border price (fob) plus internal distribution and VAT, whereas for an importing country, it is the import border price (this included product cost, insurance and freight) plus internal distribution cost and VAT. Both

\footnotetext{
${ }^{22}$ For instance, in our GMM estimations relying on the STATA package "xtabond2", we include two different measures of resource endowment as excluded instruments. See results section for details.

23 See Plante (2014) for some discussions on the advantages of the price-gap approach.
} 
measures are taken from the cross-country fuel price survey obtained from IMF Fiscal Affairs Department. See Table 8 of the "Appendix" for the top "subsidisers" in our sample.

For the supply model, the dependent variable is the annual average retail pump-price of gasoline in country $n$ for time period $t$, measured in \$US per litre. The primary independent variable, the marginal supply cost, is the wholesale price at regional hubs, ${ }^{24}$ plus downstream transportation and distribution costs, also measured in \$US per litre. Both price series were obtained from the IMF Fiscal Affairs Department and were deflated using the consumer price index $(\mathrm{CPI}),(2011=100)$, which we obtained from the World Development Indicators (WDI) database.

For market concentration, the main challenge is the lack of appropriate data on market shares across the downstream segment of petroleum markets in developing countries (Bacon and Kojima 2010). To address this problem, we compute the Herfindhal-Hirschman index (HHI) across sampled countries using two facts and assumptions. First, one of the main attributes of the petroleum industry is the extensive vertical integration of the supply chain, which usually encompasses production, refining, distribution and marketing (Barrera-Rey 1995; OECD 2013). Second, refiners own a large portion of retail outlets or have strong, restrictive contractual relationships with gasoline retailers, and this type of refinerretailer relationship appears stronger in developing jurisdictions of the world due to weak levels of corporate governance and regulatory effectiveness (Marchak 2003).

Given the discussions above, we exploit the strong vertical integration across developing regions to compute the Herfindahl-Hirschman Index (HHI) $H_{\mathrm{nt}}$, following three steps. First, we collected annual production information across domestic refiners and downstream operators from the "Worldwide Petroleum Survey", which covers operating data for 650 operators across our sample. Second, because for many countries, petroleum demand exceeds domestic refinery capacity, we treated supply from imports as an alternative producer with its own market share: we collected the import data from the US Energy Information Administration (EIA) database. Third, we then derived the market share for each producer as the ratio of their output to total market supply. From here, it is a small step to derive HHI, which we calculated for each country as the summation of the squared market shares. As shown in Table 1, our computed HHI estimates show a high degree of market concentration across our sample, and they are consistent with estimates in Kojima et al. (2010), Bacon and Kojima (2010) and Sharma and Gundimeda (2017) who measured market concentration for some Sub-Saharan Africa and Asian countries.

In addition to controlling for market concentration via the HHI, we also specified a variable in $\mathbf{x}_{n t}^{\prime}$ to control for the impact of prevailing national supply constraints within our model by including changes in inventories/stocks (Marion and Muehlegger 2011). We obtain information on gasoline stock changes from the IEA database. For the demand equation, the dependent variable is gasoline consumption, taken from the US Energy Information Administration (EIA) database. The demand shifters in $\mathbf{z}_{n t}^{\prime}$ are income and population. Both variables were obtained from the World Development Indicators (WDI) database. Table 1 presents the descriptive statistics for our sample, which is an unbalanced panel of 68 countries over the period 2000-2013.

\footnotetext{
${ }^{24}$ For oil exporting countries, this is the domestic refinery-gate cost adjusted for downstream costs, while for importing countries, marginal costs as derived using the nearest producer-exporter using downstream costs that reflect transport distances from producing areas.
} 


\section{Results}

\subsection{Endogeneity of Fuel Subsidy}

We rigorously examine the possible endogeneity of fuel subsidies using the Hausman specification test, which requires the identification of an exogenous variable that influences gasoline price subsidies but does not directly influence retail gasoline prices. It is well established in the literature (e.g. IEA 2012; van Benthem 2015) that oil producing countries tend to transfer or distribute oil rents to their citizens as part of a social welfare package using fuel subsidies. Hence, we use resource endowment (represented by petroleum reserves, obtained from the EIA database $)^{25}$ to instrument for the endogenous subsidy variable.

In the first stage of the Hausman test, we estimate an OLS model where we specified $S_{n t}$ as a function of resource endowment $\left(\right.$ Endow $\left._{n t}\right)$ and other exogenous variables in (9). We find the coefficient on Endow $w_{n t}$ to be positive and statistically significant at the $1 \%$ level, indicating that oil-endowed countries are more likely to intervene in domestic gasoline markets via subsidies. Hence, Endow ${ }_{n t}$ can be considered as a valid instrument for $S_{n t}$. In the second stage of the Hausman test, the residual from the $S_{n t}$ model is then specified as an explanatory variable in the price model in (9), and we find the estimated parameter on the added residual to be statistically significantly different from zero. ${ }^{26}$ Hence, we reject the null that $S_{n t}$ is exogenous, confirming our suspicion that it is endogenous within the price model (9). We repeat the Hausman specification test using the alternative measure "fuel share of total export", which we obtained from the World Trade Organisation (WTO) database. We obtain the same underlying results in qualitative terms. Consequently, we proceed with our GMM model set-up which allows us to address the complications arising from the lagged dependent variables, as well as the endogeneity of $S_{n t}$.

\subsection{Pass-Through Regressions}

Our main pass-through results are reported in Table 2, which we estimated in levels. ${ }^{27}$ The resulting marginal cost coefficient in the levels specification lends itself to the intuitive interpretation of a cent-for-cent pass-through, which is theoretically more meaningful (see Meyler 2009; Nakamura and Zerom 2010). Moreover, the pass-through coefficient from a logged pricing rule is an exponent and the prices are not additive. It is also the case that the equation in levels will better capture pass-through for instances where marginal supply costs rise significantly, which might be smoothened by the logged model.

\footnotetext{
${ }^{25}$ Given the fixed effects in our analysis, this external instrument is appealing because it varies across sampled countries, as well as over time. Second, and more importantly, this resource endowment variable is exogenous to the demand and supply side of our model, since petroleum reserves are exogenously determined by nature. Hence, it is reasonable to argue that the instrument is less likely to be plagued by endogeneity concerns. The use of petroleum reserves as an instrument could focus on the cross-sectional variation only but even though reserves are exogenously determined by nature that does not mean that measured reserve estimates are fixed across time since engineering estimates are revised even when exploration effort is unchanged. Consequently, we argue that our present intertemporal variation approach is less liable to measurement error.

26 Results are available upon request.

27 We do not explore the log specification given that some of our variables have zeros and negative values.
} 
Table 1 Descriptive statistics

\begin{tabular}{lccc}
\hline Variables & Mean & SD & Observations \\
\hline Retail gasoline price (\$ US per litre) & 1.158 & 0.764 & 819 \\
Marginal cost (\$ US per litre) & 0.853 & 0.323 & 819 \\
Gasoline demand (thousand barrels per day) & 72846.19 & 200891.9 & 819 \\
Per capita income (2011 US \$ ppp) & 9690.07 & 15793.94 & 819 \\
Total population (million, people) & 68.78 & 207.05 & 819 \\
HHI (sum of square of market shares) & 6399.27 & 3283.6 & 819 \\
Fuel subsidy (\$ US per litre) & 0.091 & 0.207 & 819 \\
Stock changes (mtoe) & -18.17 & 352.03 & 819 \\
Resource endowment (petroleum reserves, bbl) & 4.95 & 17.59 & 819 \\
Fuel share of total export (\%) & 20.46 & 30.13 & 819 \\
\hline
\end{tabular}

The first column of Table 2 (OLS-1) presents estimates of the standard pass-through regression in (9) where we estimated a pooled OLS model as a baseline. The specification in the second column (OLS-2) includes fixed country effects to account for constant differences in gasoline price setting conditions across countries. Our main results are derived from the SYS-GMM specification in the third column where we use petroleum reserves as an external instrument for petroleum subsidies. To check the sensitivity of our results, we re-estimate the GMM model using fuel share of export as the excluded instrument, column 4. In general, the GMM results (columns 3 and 4) are stable and sensible, with the coefficient of the lagged retail gasoline price lying between the baseline OLS and FE estimates (Roodman 2009). For the IV specification results to be reliable, it is important to ensure that two critical conditions are met: (1) instrument relevance and (2) instrument validity, i.e. the instrument (s) ought to be correlated with the endogenous regressors and at the same time orthogonal to the random errors.

While the relevance of our instruments is confirmed by the Hausman specification test above, we need to cast some light on the orthogonality conditions. Within the GMM specification, we are able to test for instrument validity based on overidentifying restrictions in the context of an overidentified model where $l>k$, i.e. there are $l$ excluded instruments more than $k$ right-hand endogenous variables. In this case, we can use the Hansen (1982) test of overidentifying restrictions, which is a joint test of the hypotheses that the instruments, excluded and included, are independently distributed of the error process and that they are properly excluded from the model. As shown in Table 2, the $\chi^{2} p$ value on the Hansen $J$ statistic on the GMM estimates are 0.165 and 0.144 respectively, failing to reject the null that our instruments are valid. We see in columns (3) and (4) that the parameter estimates across both specifications are qualitatively similar, so that we can conclude that our main results appear robust to alternative choice of instruments.

Focusing on these GMM results, it can be seen that most of the coefficients are in line with expectations and they are largely statistically significant. Both GMM regressions reflect incomplete pass-through. The short-run pass through coefficient in the SYSGMM specification in the third column of Table 2, where we use petroleum reserves as an external instrument for petroleum subsidies, is 0.67 with a standard error of 0.14 indicating that in the short-run pass through is significantly less than unity or $100 \%$ at the one percent significance level. The intertemporal partial adjustment coefficient indicates that it takes around 5 years to return to equilibrium after a price shock. The long 
Table 2 Pass-through regressions

\begin{tabular}{|c|c|c|c|c|}
\hline \multirow{2}{*}{ Dep.var: $\boldsymbol{P}_{n t}^{d}$} & \multicolumn{2}{|l|}{ OLS } & \multicolumn{2}{|l|}{ IV } \\
\hline & (1) & (2) & (3) & (4) \\
\hline \multirow{2}{*}{$P_{n t-1}^{d}$} & $0.312 * * *$ & $0.168 * * *$ & $0.204 * * *$ & $0.206^{* * *}$ \\
\hline & $(0.117)$ & $(0.048)$ & $(0.053)$ & $(0.055)$ \\
\hline \multirow[t]{2}{*}{$P_{n t}^{w} \equiv M C_{n t}$} & $0.446 * * *$ & $0.758 * * *$ & $0.670 * * *$ & $0.643 * * *$ \\
\hline & $(0.117)$ & $(0.140)$ & $(0.139)$ & $(0.152)$ \\
\hline \multirow[t]{2}{*}{$S_{n t}$} & $-1.003 * * *$ & $-0.809 * * *$ & $-1.093 * * *$ & $-1.113^{* * *}$ \\
\hline & $(0.155)$ & $(0.114)$ & $(0.074)$ & $(0.088)$ \\
\hline \multirow[t]{2}{*}{$H H I_{n t}$} & $0.187 * * *$ & 0.131 & $0.198 * * *$ & $0.183 * * *$ \\
\hline & $(0.042)$ & $(0.176)$ & $(0.056)$ & $(0.060)$ \\
\hline \multirow[t]{2}{*}{ Stock $_{n t}$} & -0.001 & -0.010 & $-0.017 * * *$ & $-0.017 * * *$ \\
\hline & $(0.001)$ & $(0.010)$ & $(0.010)$ & $(0.010)$ \\
\hline \multirow[t]{2}{*}{ Constant } & $0.256 * * *$ & $0.414 * * *$ & $0.239 * * *$ & $0.269 * * *$ \\
\hline & $(0.069)$ & $(0.135)$ & $(0.085)$ & $(0.100)$ \\
\hline \multicolumn{5}{|l|}{ Long-run Estimates } \\
\hline \multirow[t]{2}{*}{ Pass-through } & $0.648 * * *$ & $0.911^{* * *}$ & $0.842 * * *$ & $0.809 * * *$ \\
\hline & $(0.091)$ & $(0.140)$ & $(0.145)$ & $(0.161)$ \\
\hline \multirow[t]{2}{*}{ Subsidy } & $-1.457 * * *$ & $-0.973 * * *$ & $-1.372 * * *$ & $-1.402 * * *$ \\
\hline & $(0.053)$ & $(0.133)$ & $(0.079)$ & $(0.104)$ \\
\hline \multirow[t]{2}{*}{ Market concentration } & $0.272 * * *$ & 0.158 & $0.249 * * *$ & $0.231 * * *$ \\
\hline & $(0.035)$ & $(0.211)$ & $(0.068)$ & $(0.074)$ \\
\hline Country/region effects & - & Yes & Yes & Yes \\
\hline Time effects & Yes & Yes & Yes & Yes \\
\hline$R^{2}$ & 0.802 & 0.710 & 0.781 & 0.782 \\
\hline$p$ value AR (1) test & - & - & 0.023 & 0.024 \\
\hline$p$ value AR (2) test & - & - & 0.250 & 0.253 \\
\hline$p$ value Hansen test & - & - & 0.165 & 0.144 \\
\hline Number of observations & 751 & 751 & 751 & 751 \\
\hline
\end{tabular}

Robust standard errors in parentheses are clustered at country level. ***,** and * denote statistical significance at $1 \%, 5 \%$ and $10 \%$, respectively. Arellano-Bond tests for first and second order serial correlation in the first differenced residuals. These are asymptotically distributed $\mathrm{N}(0,1)$ under the null of no serial correlation. Hansen test of the over-identifying restrictions is asymptotically Chi square distributed under the null of instrument validity. Chi square $p$ value are reported

run pass-through coefficient is 0.84 indicating the possibility of some incomplete passthrough even after 5 years, but the value is not significantly different from unity at the one percent level of significance. Hence, our point estimate is that only around 8 cents of a 10 cent shock in costs is passed through to retail gasoline prices in the long run. In the short run the short-fall is much greater. Moving on to the two sources of price distortions, the presence of a fuel subsidy regime is associated with lower retail gasoline prices, given that the coefficient on the subsidy variable is consistently negative and statistically significant at $1 \%$ across all estimated models (see Table 2). As expected, the mark-up on prices arising from the exercise of market power is reflected by the positive coefficient on HHI which indicates that increased market concentration results in 
higher prices. In the IV specifications, the long run estimates of fuel subsidy distortions on retail prices are -1.37 and -1.40 , compared to the long-run mark-up from market power 0.19 and 0.18 .

At first glance, the distortions arising from petroleum subsidies appear to outweigh the effects of market concentration. Furthermore, ceteris paribus, treating the three long-run estimates in Table 2 as the sources of retail gasoline price shocks, the price distortions from fuel subsidies exceed the combined effect of price shocks arising from cost pass-through and market power-a striking finding from the analysis. We explore the implications of these findings in greater detail in Sect. 7.3.

\subsection{Robustness Checks}

Despite the IV strategy adopted in this study, there might be concerns that our results simply reflect heterogeneity between oil-rich and less-endowed countries in the sample. To address these concerns, we undertake additional robustness checks on our findings by restricting our sample to a subset of less-endowed countries (i.e. countries with fuel share of export less than 10\%) and re-estimating the models in Table 2. The results of the re-estimated pass-through regressions are presented in Table 3. As seen in the results presented in this table, the estimates from the restricted model are slightly different, quantitatively, the results are quite similar in qualitative terms: the subsidy distortions are still negative and larger than the market power distortions and shocks from marginal cost. These findings suggest that our instrumentation strategy is robust to heterogeneity and endogeneity concerns, as well as to our data sampling. ${ }^{28}$

\subsection{Market Demand Estimations}

In order to derive the semi-elasticity of gasoline demand $\partial \ln Y_{n t} / \partial P_{n t}^{d}=\hat{\eta}$, we estimate (11) with the price variable in levels while the other variables are in log transformations. The market demand regressions are presented in Table 4 . The endogeneity of prices in the econometric estimation of gasoline demand should be apparent now given the influence of domestic fuel pricing policy (subsidies) on retail gasoline prices. Yet, identifying the semielasticity of demand is an important input in our empirical analysis. For this reason, we explore a GMM estimation for the estimated demand model.

The coefficient on lagged gasoline demand is 0.74 (again falls between the OLS and FE estimates), indicating a sluggish adjustment process which is consistent with the intuition that changes in energy use usually adjust partially towards their expected long-run, in response to changes in prices, income, technology and so forth. We estimate short-run and long-run semi-elasticities at the sample mean at values of -0.11 and -0.42 , respectively. The semi-elasticities imply that a $\$ 1$ increase in gasoline prices across sampled countries, where the sample mean price is US\$PPP 1.16 (i.e. an $86 \%$ increase) resulted in a $11 \%$ decline in consumption in the short run. In the long-run, the response increased to $42 \%$. The main implication of these findings is the inelastic demand for gasoline.

${ }^{28}$ Further robustness tests are presented in the "Appendix". 
Table 3 Pass-through regressions (restricted sample)

\begin{tabular}{|c|c|c|c|c|}
\hline \multirow{2}{*}{ Dep.var: $\boldsymbol{P}_{n t}^{d}$} & \multicolumn{2}{|l|}{ OLS } & \multicolumn{2}{|l|}{ IV } \\
\hline & (1) & (2) & (3) & (4) \\
\hline \multirow{2}{*}{$P_{n t-1}^{d}$} & $0.273 * * *$ & $0.126^{* * * *}$ & $0.167 * * *$ & $0.169 * * *$ \\
\hline & $(0.107)$ & $(0.017)$ & $(0.031)$ & $(0.031)$ \\
\hline \multirow[t]{2}{*}{$P_{n t}^{w} \equiv M C_{n t}$} & $0.617 * * *$ & $1.082 * * *$ & $0.879 * * *$ & $0.855 * * *$ \\
\hline & $(0.170)$ & $(0.136)$ & $(0.192)$ & $(0.193)$ \\
\hline \multirow[t]{2}{*}{$S_{n t}$} & $-1.123 * * *$ & $-0.912 * * *$ & $-1.164 * * *$ & $-1.167 * * *$ \\
\hline & $(0.173)$ & $(0.035)$ & $(0.151)$ & $(0.153)$ \\
\hline \multirow[t]{2}{*}{$H H I_{n t}$} & $0.168 * * *$ & 0.030 & $0.165^{*}$ & $0.161 *$ \\
\hline & $(0.044)$ & $(0.143)$ & $(0.092)$ & $(0.094)$ \\
\hline \multirow[t]{2}{*}{ Stock $_{n t}$} & -0.001 & $-0.019 * * *$ & $-0.019 * *$ & $-0.019 * * *$ \\
\hline & $(0.001)$ & $(0.005)$ & $(0.010)$ & $(0.010)$ \\
\hline \multirow[t]{2}{*}{ Constant } & $0.185 * *$ & $0.208 * * *$ & 0.161 & 0.161 \\
\hline & $(0.073)$ & $(0.130)$ & $(0.133)$ & $(0.133)$ \\
\hline \multicolumn{5}{|l|}{ Long-run Estimates } \\
\hline \multirow[t]{2}{*}{ Pass-through } & $0.849 * * *$ & $1.239 * * *$ & $1.055^{* * *}$ & $1.029 * * *$ \\
\hline & $(0.148)$ & $(0.144)$ & $(0.208)$ & $(0.211)$ \\
\hline \multirow[t]{2}{*}{ Subsidy } & $-1.547 * * *$ & $-1.044 * * *$ & $-1.398 * * *$ & $-1.404 * * *$ \\
\hline & $(0.184)$ & $(0.041)$ & $(0.177)$ & $(0.181)$ \\
\hline \multirow[t]{2}{*}{ Market concentration } & $0.232 * * *$ & 0.035 & $0.198 *$ & $0.194 *$ \\
\hline & $(0.049)$ & $(0.163)$ & $(0.109)$ & $(0.113)$ \\
\hline Country/region effects & - & Yes & Yes & Yes \\
\hline Time effects & Yes & Yes & Yes & Yes \\
\hline$R^{2}$ & 0.672 & 0.583 & 0.644 & 0.646 \\
\hline$p$ value $\mathrm{AR}$ (1) test & - & - & 0.110 & 0.106 \\
\hline$p$ value AR (2) test & - & - & 0.091 & 0.095 \\
\hline$p$ value Hansen test & - & - & 0.981 & 0.972 \\
\hline Number of observations & 463 & 463 & 463 & 463 \\
\hline
\end{tabular}

Robust standard errors in parentheses are clustered at country level. ***, ** and * denote statistical significance at $1 \%, 5 \%$ and $10 \%$, respectively. Arellano-Bond tests for first and second order serial correlation in the first differenced residuals. These are asymptotically distributed $\mathrm{N}(0,1)$ under the null of no serial correlation. Hansen test of the over-identifying restrictions is asymptotically Chi square distributed under the null of instrument validity. Chi square $p$ value are reported

\subsection{Key Market Parameters}

Now we examine the central parameter estimates of our long-run market measures and the countervailing trade-off reflecting second-best policy outcomes; these are given in Table 5. Three hypotheses are central to this paper which has examined retail gasoline markets in emerging economies during the period 2000-2013, a period of intense world interest in climate change and the United Nations climate change conferences. We have rejected the null hypothesis that retail gasoline markets are competitive. We have rejected the null hypothesis that there is complete pass-through from marginal cost to retail gasoline prices, certainly in the short run. We have also rejected the null hypothesis that there is no subsidy 
Table 4 Empirical results for market demand regressions $\ln \mathrm{Y}_{\mathrm{nt}}$

\begin{tabular}{llll}
\hline & $\begin{array}{l}\text { OLS } \\
(1)\end{array}$ & $\begin{array}{l}\text { FE } \\
(2)\end{array}$ & $\begin{array}{l}\text { IV } \\
(3)\end{array}$ \\
\hline$Y_{n t-1}$ & $0.949^{* * *}$ & $0.547^{* * *}$ & $0.741^{* * *}$ \\
& $(0.014)$ & $(0.105)$ & $(0.146)$ \\
$P_{n t}^{d}$ & $-0.045^{* *}$ & $-0.104^{* * *}$ & $-0.094^{*}$ \\
& $(0.022)$ & $(0.037)$ & $(0.055)$ \\
Inc ${ }_{n t}$ & $0.055^{* * *}$ & $0.302^{*}$ & $0.300^{*}$ \\
& $(0.019)$ & $(0.156)$ & $(0.170)$ \\
$P o p_{n t}$ & $0.048^{* * *}$ & 0.261 & $0.225^{*}$ \\
& $(0.015)$ & $(0.228)$ & $(0.136)$ \\
Long-run semi-elasticity & $-1.030^{*}$ & $-0.266^{* *}$ & $-0.422^{*}$ \\
& $(0.556)$ & $(0.112)$ & $(0.224)$ \\
Country effects & - & Yes & Yes \\
Time effects & - & Yes & Yes \\
$R^{2}$ & 0.989 & 0.980 & 0.985 \\
$p$ value AR (1) test & - & - & 0.002 \\
$p$ value AR (2) test & - & - & 0.048 \\
$p$ value Hansen test & - & - & 0.370 \\
\hline
\end{tabular}

Robust standard errors in parentheses are clustered at country level. $* * *, * *$ and $*$ denote statistical significance at $1 \%, 5 \%$ and $10 \%$, respectively. Arellano-Bond tests for first and second order serial correlation in the first differenced residuals. These are asymptotically distributed $\mathrm{N}(0,1)$ under the null of no serial correlation. Hansen test of the over-identifying restrictions is asymptotically Chi square distributed under the null of instrument validity. Chi square $p$ value are reported

effect in retail gasoline markets. These broad conclusions point to two types of possible inefficiency in the allocation of resources: market failure and policy/government failure. Using the central estimates in Table 5, we present the key parameters in the analysis and we consider each of these hypotheses in turn.

The first hypothesis to be rejected is that the retail gasoline market is completely competitive. We show that the retail gasoline market is strongly driven by income change; it is also responsive to price change, but the response is inelastic. We parameterised the semielasticity of market demand, $\eta$, in order to identify the role of market power which has two parametric components: the first is the market conduct parameter, $\Theta$, which is then scaled up by the inverse of the semi-elasticity of demand. The semi-elasticity was estimated at -0.42 , so that the market elasticity, $\varepsilon$, is -0.49 if normalised to the sample mean. This semi-elasticity of demand parameter is essential to identifying the market conduct parameter in the price equation, and this market conduct parameter lies in the unit interval (zero in the case of a completely competitive market, and one in the case of pure monopoly).

We estimate the long run value of the market conduct parameter in Table 5 to be 0.122 , significantly greater than zero at the $5 \%$ level of significance on a one-tail test. Therefore, while the retail gasoline market is on average not perfectly competitive, at the same time, strong market power mark-up is not a dominant feature of the market at this level. Scaling up the estimate: $\hat{\Theta}=0.122$ by the inverse semi-elasticity: $\hat{\eta}=0.411$ and multiplying by the sample mean of the concentration index: $\overline{H H I}=0.642$, we find that the market power 


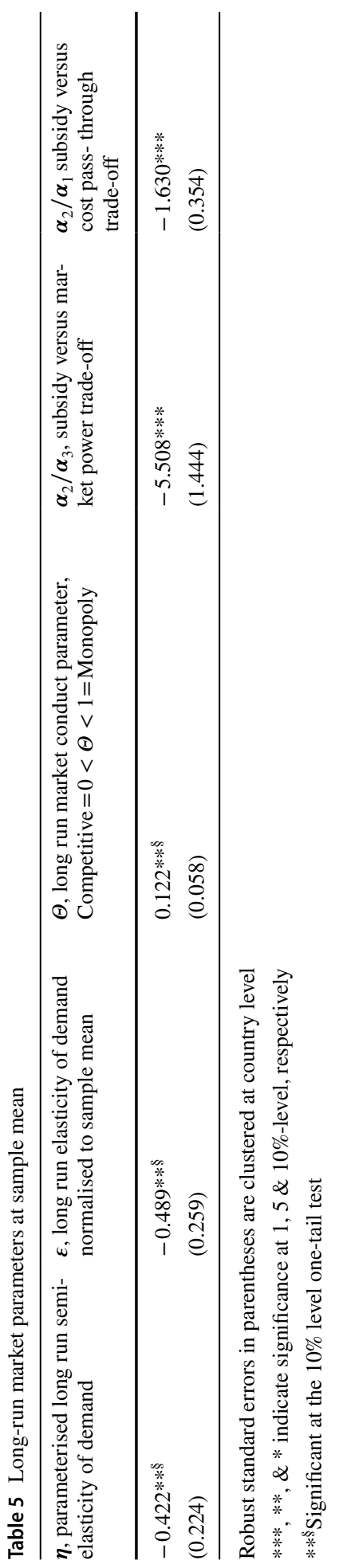


component in the price level equation increases the market price at the sample mean by 0.191 \$USPPP or about $16.47 \%$ of the retail price of gasoline at the sample mean. We conclude therefore that while a degree of market power is exercised, it is only relatively weak: market power mark-up is statistically significant but not quantitatively dominant. We see this clearly when we examine the other determinants of the retail price: marginal cost passthrough and subsidies.

The second null hypothesis that engages our attention is that marginal cost is completely passed through to retail prices in the domestic gasoline market. Using the linear price equation model of Table 2, where the short run pass-through of retail price with respect to marginal cost is 0.67 , we reject the hypothesis that this short run pass-through elasticity is not significantly different from unity at the $1 \%$ level of significance. However, in the long run results indicate that only just over 8 cent from a 10 cent shock to marginal cost was passed through to retail gasoline consumers during the period 2000-2013, ${ }^{29}$ despite the evidence of some, albeit muted, market power. ${ }^{30}$ It might be argued that mitigating the pass-through of rising international prices to retail domestic prices is an effective second-best countervailing policy designed to reduce the impact of market power on the efficient allocation of resources; however, this degree of policy offset considerably exceeds the adjustment needed for a second-best optimal replacement, and it is possible that an income redistribution objective is the main determinant of this degree of retail price offset.

The third hypothesis to be investigated pertains to the question of whether there was no additional impact on retail gasoline prices from direct fuel subsidy effects. Again, the results in Table 2 and 3 decisively reject this hypothesis. In fact, the distortion (price-reducing) effect of these gasoline subsidies exceed the sum of the shocks from pass-through and market power. Since these subsidies are most often used by countries with large natural resource endowments, it could be argued that their governments are using gasoline subsidies to directly redistribute the wealth represented by the natural resource endowment to gasoline consumers. Whether heavily subsidised gasoline consumers are the most deserving candidates for wealth redistribution is clearly outside the scope of this paper.

In column 4 of Table 5, we calculate the policy trade-offs that are implicit in the estimates in Tables 2, 3, and 4. The long run estimate of the ratio for $\alpha_{2} / \alpha_{3}$ is -5.51 . This is the trade-off between gasoline subsidies on the retail price versus the market power impact from concentration. The subsidy overcompensates for market power to the order of 4.5, and this is in addition to the reduced pass-through of marginal cost. Again, this reinforces the notion above that fuel-subsidizing countries (mostly oil-rich nations) in our sample, give their gasoline consumers retail prices that are a small fraction of international prices. ${ }^{31}$ Also, in Table 5, the long run estimate of the ratio for $\alpha_{2} / \alpha_{1}$ is -1.63 which indicates that gasoline subsidies in our sample more than compensate for cost pass-through.

\subsection{Policy Implications: Market Failure versus Government Failure}

How can these empirical findings be related to economic policy making? Typically in emerging economies, there might be at least four objectives in framing energy policy: (a)

\footnotetext{
29 This was a period of generally rising international oil prices.

30 This reduction in the pass-through of marginal cost already wipes out $83 \%$ of the mark-up on price due to market power.

31 This is consistent with the reality that, in those countries the dominant gasoline retailers are often stateowned enterprises who have little or no incentive to maximise refinery margins.
} 
mitigate the effect of market power on retail gasoline prices; (b) signal the social marginal cost of gasoline consumption arising from its impact on climate change; (c) redistribute income to the poorest consumers by preventing the full pass-through of international prices or marginal gasoline costs; (d) monetise the natural resource wealth endowment for the whole population through subsidy of retail gasoline prices.

The first two objectives address the issue of market failure in the efficient allocation of resources, and there is potential for inefficiency if these policies are poorly designed. The third and fourth objectives address the issue of income and wealth distribution and there is potential for policy-failure or government-failure if these are poorly designed. On the other hand, the theory of the second-best tells us that departures from efficient marginal cost-based prices in one direction can be compensated by off-setting adjustments to the price-marginal cost ratio in the opposite direction to achieve a second-best allocation of resources. ${ }^{32}$

In considering the first two objectives, there is a trade-off between mitigating market power and signalling the cost of climate change, encapsulated in the well-known saying that the monopolist is the conservationist's friend-see Medlock (2011) for a discussion of this idea. In this sample, we find that market power is present but muted, and as a consequence, retail gasoline prices may not align well with the levels required for vigorous anticlimate change policy. ${ }^{33}$

Turning to the third and fourth objectives, second-best policy would support some consumption subsidy or offset to retail prices in order to meet equity considerations for consumers if there is strong market power. However, while we find mild upward price distortions from market concentration, the second-best equity-based subsidy offset to mitigate the estimated distortion from market power is, on average, highly excessive.

Figure 2 offers a visual evolution of the comparative size of both distortions across the subsidisers in our sample using the average elasticity-form estimates for market power and subsidies. It is shown that the excessive downward price distortion from subsidies versus market power mark-up was persistent and generally growing over the period under consideration. ${ }^{34}$ Therefore, we conclude that the potential for policy failure has strongly exceeded the potential for market failure in this sample.

\section{Concluding Remarks}

What did we do in this paper? The purpose was to investigate whether there is a countervailing offset from the two major sources of market distortions in petroleum markets for a sample of 68 developing economies over the period 2000-2013. We explored the possibility that these two offsetting distortions can conceivably achieve a second-best optimum. We began by setting out a model of price determination identifying three key determinants of the observed retail gasoline prices: the extent of pass-through of marginal cost; policybased subsidy and refiner market power, conditional on the Herfindahl-Hirschman concentration index. Identifying the market conduct parameter requires a simultaneous equation model of price setting and market demand. Since we have access to international marginal

\footnotetext{
32 See Lipsey and Lancaster (1956), Farrell (1958) and Davis and Whinston (1962) for classic treatments.

33 It can be argued that current levels of retail gasoline prices across sampled countries are unlikely to internalise the marginal environmental damage caused by increased gasoline consumption.

34 Clearly it can be seen that the subsidy effect declined in the period 2008/09, possibly in response to the global financial crisis which led to declines in commodity prices and which might have constrained national spending/budgets on fuel subsidies..
} 


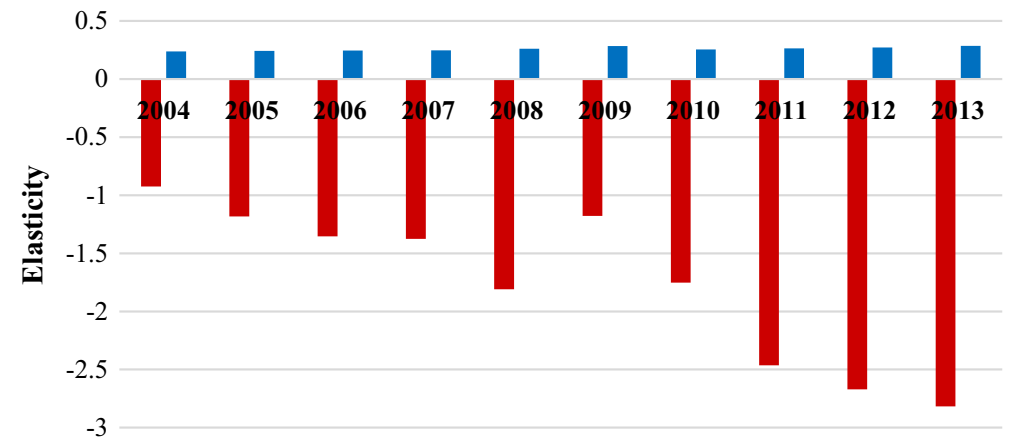

n Subsidy = Market Power

Fig. 2 Average price distortions across subsidisers, 2004-2013

cost data, the model is recursive. This allowed us to identify market conduct and semielasticity of demand (the two components of refiner market power) and to model the lagged adjustment of the gasoline market.

We conclude from the empirical estimation that market power is present but that its effect is relatively weak in the sense that the resulting upward distortion of prices above marginal costs is strongly exceeded by the countervailing downward distortion of prices below marginal cost arising from incomplete pass-through and from additional fuel price subsidies. Both the incomplete short run pass-through effect and the subsidy effect are statistically significant to a strong degree. We discussed whether there were second-best grounds for this kind of off-set to prices, but the off-set seems to be excessive for the market power distortion that we measured. The motivation for the large off-set to marginal costs could be based on equity or endowment-distribution reasons, but in any case, the off-set runs strongly counter to the optimal policies for signalling the social marginal cost of climate change. We conclude that in energy policy there is the potential for two kinds of inefficiency in the allocation of resources, market failure and policy failure; and we argue that the empirical effect of policy failure far exceeds the measured impact of market failure in this sample of countries.

Finally, this study examines the countervailing distortions arising from fuel subsidies and refiner market power in petroleum markets across a sample of developing countries. It is important to examine the offsets for other widely subsidised energy products, especially electricity which often imposes similar economic costs on the economy. Secondly, quantifying the impact of these offsets on future/projected petroleum related carbon emissions is crucial to the cost-benefit analysis of fuel subsidy reforms.

Our analysis is for a historical period up to 2013. Clearly there has been some deregulation of fuel markets in developing countries recently. Therefore, the question arises whether the distortion in price signals is likely to be maintained in future. Much depends on the trade-off involved in replacing administered pricing by state-owned companies with deregulated pricing by new private sector entrants, and whether governments disturbed by popular opposition to the subsequent price rises will revert to further off-setting subsidy. Further research is needed into this continuously evolving and important issue.

Open Access This article is distributed under the terms of the Creative Commons Attribution 4.0 International License (http://creativecommons.org/licenses/by/4.0/), which permits unrestricted use, distribution, and reproduction in any medium, provided you give appropriate credit to the original author(s) and the source, provide a link to the Creative Commons license, and indicate if changes were made. 


\section{Appendix}

See Tables 6, 7, 8, 9, and 10

Table 6 Classification of countries in the data sample based on oil endowment

\begin{tabular}{ll}
\hline Classification & Country \\
\hline Oil-rich & Algeria, Angola, Azerbaijan, \\
& Bahrain, Bolivia, Cameroon, \\
& Cote d' Ivoire, Ecuador, Egypt, \\
& Indonesia, Iran, Libya, Malaysia, \\
& Nigeria, Oman, Qatar, Russia, \\
& Sudan \\
Argentina, Bangladesh, Benin, & Botswana, Brazil, Burkina Faso, \\
Burundi, China, Colombia, Costa & Rica, Cyprus, Dem. Rep. Congo, \\
Dominican Republic, Ethiopia, & Ghana, Guatemala, Guinea, \\
& Haiti, India, Kenya, L.A.O. PDR, \\
& Lesotho, Lithuania Madagascar, \\
& Malawi, Mali, Malta, Mauritania, \\
& Mauritius, Morocco, Mozam- \\
& bique Namibia, Nepal, Nicara- \\
gua, Niger, Pakistan, Panama, & Peru, Philippines, Rwanda, \\
& Senegal, South Africa, Sri Lanka, \\
& Swaziland, Tanzania, Thailand, \\
Tunisia & \\
Uganda, Uruguay, Zambia
\end{tabular}

Country classification is based on Venables (2016)

Table 7 Definition of variables and sources

\begin{tabular}{|c|c|c|}
\hline Variable & Definition & Source \\
\hline Retail gasoline price & $\begin{array}{l}\text { Inflation-adjusted retail gasoline price (US \$ per } \\
\text { litre) }\end{array}$ & IMF \\
\hline $\begin{array}{l}\text { Marginal supply cost of } \\
\text { gasoline }\end{array}$ & $\begin{array}{l}\text { Inflation-adjusted ex-refinery hub price (US \$ per } \\
\text { litre) }\end{array}$ & IMF \\
\hline Gasoline demand & Gasoline consumption (thousand barrels per day) & EIA \\
\hline Per capita income & GDP per capita in 2011 US \$ ppp & WDI \\
\hline Population & Total population (number of people in millions) & WDI \\
\hline $\begin{array}{l}\text { Herfindahl-Hirschman } \\
\text { Index (HHI) }\end{array}$ & Derived from domestic production $\&$ fuel imports & World refinery survey \\
\hline Fuel subsidy & $\begin{array}{l}\text { Domestic minus international reference price (US \$ } \\
\text { per litre) }\end{array}$ & Authors calculation \\
\hline Stock changes & Stocks at the beginning minus year end stocks (mtoe) & IEA \\
\hline Resource endowment & Petroleum reserves, bbl & EIA \\
\hline Resource endowment (2) & Fuel share of total export (\%) & WTO \\
\hline
\end{tabular}


Table 8 Top fuel subsidisers in 2013

Table 9 First stage of IV regression

\begin{tabular}{llclll}
\hline By dollar value & & & \multicolumn{2}{l}{ By share of GDP } \\
\cline { 1 - 2 } \cline { 5 - 6 } Rank & Country & $\begin{array}{c}\text { Total subsi- } \\
\text { dies }(\$ B)\end{array}$ & & Country & $\begin{array}{c}\text { Share of } \\
\text { GDP }(\%)\end{array}$ \\
\hline 1 & Russia & 127.6 & & Iran & 17.1 \\
2 & Indonesia & 72.9 & & Libya & 14.9 \\
3 & Iran & 62.9 & & Algeria & 9.1 \\
4 & Malaysia & 20.5 & & Indonesia & 8.4 \\
5 & Algeria & 19.4 & & Oman & 8.2 \\
6 & Libya & 9.8 & & Bolivia & 8.2 \\
7 & Ecuador & 7.7 & & Ecuador & 8.1 \\
8 & Angola & 7.3 & & Malaysia & 6.5 \\
9 & Nigeria & 6.6 & Russia & 6.1 \\
10 & Oman & 6.3 & Angola & 5.9 \\
\hline
\end{tabular}

IMF (2015)

\begin{tabular}{lll}
\hline Dependent var: $S_{n t}$ & $(1)$ & $(2)$ \\
\hline Endow $_{n t}$ & $0.003^{* * *}$ & $0.004^{* * *}$ \\
& {$[0.001]$} & {$[0.000]$} \\
Country effects & Yes & Yes \\
Year effects & Yes & Yes \\
Other controls & Yes & Yes \\
Cragg-Donald F-test & 80.36 & 423.49 \\
Instrument & Reserves $_{n t}$ & Fuelshare $_{n t}$ \\
\hline
\end{tabular}

Robust standard errors in parentheses are clustered at country level. $* * *, * *$ and $*$ denote statistical significance at $1 \%, 5 \%$ and $10 \%$, respectively 
Table 10 IV regression in levels

\begin{tabular}{lll}
\hline Dep.var: $\boldsymbol{P}_{n \boldsymbol{t}}^{d}$ & $\mathbf{( 1 )}$ & $\mathbf{( 2 )}$ \\
\hline$P_{n t-1}^{d}$ & $0.175^{* * *}$ & $0.175^{* * *}$ \\
$P_{n t}^{w} \equiv M C_{n t}$ & $(0.010)$ & $(0.022)$ \\
& $0.945^{* * *}$ & $0.943^{* * *}$ \\
$S_{n t}$ & $(0.131)$ & $(0.117)$ \\
& $-0.474^{* * *}$ & $-0.455^{* * *}$ \\
$H H I_{n t}$ & $(0.118)$ & $(0.117)$ \\
& $0.070^{* * *}$ & $0.076^{* * *}$ \\
$S t o c k_{n t}$ & $(0.018)$ & $(0.019)$ \\
Country/region effects & $-0.001^{* * *}$ & $-0.002^{* * *}$ \\
Year effects & $(0.000)$ & $(0.000)$ \\
Instrument & Yes & Yes \\
$R^{2}$ & Yes & Yes \\
$p$ value AR (1) test & Reserves & Fuel export \\
$p$ value $p$ value AR (2) test & 0.722 & 0.721 \\
$p$ value Hansen test & 0.004 & 0.005 \\
Number of observations & 0.191 & 0.190 \\
\hline
\end{tabular}

Robust standard errors in parentheses are clustered at country level. $* * *, * *$ and $*$ denote statistical significance at $1 \%, 5 \%$ and $10 \%$, respectively. Arellano-Bond tests for first and second order serial correlation in the first differenced residuals. These are asymptotically distributed $\mathrm{N}(0,1)$ under the null of no serial correlation. Hansen test of the over-identifying restrictions is asymptotically Chi square distributed under the null of instrument validity. Chi square $p$ value are reported

\section{References}

Alm J, Sennoga E, Skidmore M (2009) Perfect competition, urbanization, and tax incidence in the retail gasoline market. Econ Inq 47(1):118-134

Angelini P, Cetorelli N (2003) The effects of regulatory reform on competition in the banking industry. J Money Credit Bank 35(5):663-684

Appelbaum E (1982) The estimation of the degree of oligopoly power. J Econom 19(2):287-299

Arellano M, Bond S (1991) Some tests of specification for panel data: Monte Carlo evidence and an application to employment equations. Rev Econ Stud 58(2):277-297

Arellano M, Bover O (1995) Another look at the instrumental variable estimation of error-components models. J Econom 68(1):29-51

Asplund M, Eriksson R, Friberg R (2000) Price adjustments by a gasoline retail chain. Scand J Econ 102(1):101-121

Atil A, Lahiani A, Nguyen K (2014) Asymmetric and nonlinear pass-through of crude oil prices to gasoline and natural gas prices. Energy Policy 65(3):567-573

Bachmeier L, Griffin J (2003) New evidence on asymmetric gasoline price responses. Rev Econ Stat 85(3):772-776

Bacon R, Kojima M (2010) Rockets and feathers: asymmetric petroleum product pricing in developing countries. Extractive Industries for Development Series, 18

Baig T, Coady D, Ntamatungiro J, Mati A (2007) Domestic petroleum product prices and subsidies: Recent developments and reform strategies. International Monetary Fund. IMF Working Paper No. 07/71

Barrera-Rey F (1995) The effects of vertical integration on oil company performance 
Beers CV, Strand J (2013) Political determinants of fossil fuel pricing. World Bank Policy Research Working Paper 6470

Blundell R, Bond S (2000) GMM estimation with persistent panel data: an application to production functions. Econ Rev 19(3):321-340

Bond S (2002) Dynamic panel data models: a guide to micro data methods and practice. Port Econ J 1(2):141-162

Borenstein S, Shepard A (2002) Sticky prices, inventories, and market power in wholesale gasoline markets. RAND J Econ 33(1):116-139

Borenstein S, Cameron AC, Gilbert R (1997) Do gasoline prices respond asymmetrically to crude oil price changes? Q J Econ 112(1):305-339

Bresnahan TF (1982) The oligopoly solution concept is identified. Econ Lett 10(1):87-92

Coady D, Gillingham R, Ossowski R, Piotrowski J, Tareq S, Tyson J (2010) Petroleum product subsidies: Costly, inequitable, and rising. International Monetary Fund Staff Position Note 10/05

Coady D, Parry I, Sears L, Shang B (2017) How large are global fossil fuel subsidies? World Dev 91:11-27

Corts KS (1999) Conduct parameters and the measurement of market power. J Econ 88(2):227-250

Davis LW (2014) The economic cost of global fuel subsidies. Am Econ Rev 104(5):581-585

Davis OA, Whinston A (1962) Externalities, welfare, and the theory of games. J Polit Econ 70(3):241-262

Delis MD, Tsionas EG (2009) The joint estimation of bank-level market power and efficiency. J Bank Finance 33(10):1842-1850

Farrell MJ (1958) In defence of public-utility price theory. Oxford Econ Pap 10(1):109-123

Hall RE (1988) The relation between price and marginal cost in US industry. J Polit Econ 96(5):921-947

Hansen L (1982) Large sample properties of generalized method of moments estimators. Econometrica 50(3):1029-1054

IMF (2013) Case studies on energy subsidy reform: lessons and implications. IMF Policy Paper January 2013

IMF (2015) How large are global energy subsidies? IMF Working Paper WP/15/105

International Energy Agency (IEA) (1999) World Energy Outlook 1999, Looking at Energy Subsidies: Getting the Prices Right. IEA, Paris

International Energy Agency (IEA) (2012) World energy outlook 2012. International Energy Agency, WEO, p 2012

Kojima M (2012) Oil price risks and pump price adjustments. World Bank Policy Research Working Paper WPS6227, World Bank

Kojima M, Matthews W, Sexsmith F (2010) Petroleum markets in Sub-Saharan Africa. The World Bank and ESMAP, Washington, DC

Kutlu L, Sickles RC (2012) Estimation of market power in the presence of firm level inefficiencies. J Econ 168(1):141-155

Larsen B, Shah A (1992) World fossil fuel subsidies and global carbon emissions. World Bank Policy Research Working Paper 1002

Lau LJ (1982) On identifying the degree of competitiveness from industry price and output data. Econ Lett 10(1):93-99

Leibenstein H (1966) Allocative efficiency vs. "X-efficiency". American Econ Rev 56(3):392-415

Lipsey RG, Lancaster K (1956) The general theory of second-best. Rev Econ Stud 24(1):11-32

Lopez RA, Azzam AM, Lirón-España C (2002) Market power and/or efficiency: A structural approach. Rev Ind Org 20(2):115-126

Marchak V (2003) Determinants of vertical integration in oil industry: Case of transition economies. Masters Thesis, Economics education and research consortium (EERC)

Marion J, Muehlegger E (2011) Fuel tax incidence and supply conditions. J Publ Econ 95(9):1202-1212

Martin S (1988) Market power and/or efficiency? Rev Econ Stat 70(2):331-335

Medlock KB (2011) The economics of energy supply. In: Hunt LC, Joanne E (eds) International handbook on the economics of energy, vol 3. Edward Elgar Publishing, Cheltenham

Meyler A (2009) The pass through of oil prices into euro area consumer liquid fuel prices in an environment of high and volatile oil prices. Energy Econ 31(6):867-881

Nakamura E, Zerom D (2010) Accounting for incomplete pass-through. Rev Econ Stud 77(3):1192-1230

Newbery DM (1995) Power markets and market power. Energy J 16(3):39-66

OECD (2013) Competition in road fuel. Organisation for economic co-operation and development, OECD DAF/COMP, 18

Parry IW, Heine MD, Lis E, Li S (2014) Getting energy prices right: from principle to practice. International monetary fund

Plante M (2014) The long-run macroeconomic impacts of fuel subsidies. J Dev Econ 107:129-143

Roodman D (2009) A note on the theme of too many instruments. Oxford Bull Econ Stat 71(1):135-158 
Shaffer S (1993) A test of competition in Canadian banking. J Money Credit Bank 25(1):49-61

Sharma D, Gundimeda H (2017) Market structure and performance of downstream oil industry: a case study of Indian National oil companies. In: International Association for Energy Economics 2017 papers and proceedings

van Benthem A (2015) Energy leapfrogging. J Assoc Energy Resour Econ 2(1):93-132

Venables AJ (2016) Using natural resources for development: why has it proven so difficult? J Econ Perspect 30(1):161-184

Weyl EG, Fabinger M (2013) Pass-through as an economic tool: principles of incidence under imperfect competition. J Polit Econ 121(3):528-583

Windmeijer F (2005) A finite sample correction for the variance of linear efficient two-step GMM estimators. J econ 126(1):25-51

Publisher's Note Springer Nature remains neutral with regard to jurisdictional claims in published maps and institutional affiliations. 